\title{
A Standard Operative Procedure for Safe-handling of Remains and Wastes of COVID-19 Patients \\ Ravi Kant Narayan ${ }^{1}$, Adil Asghar ${ }^{1}$, Rakesh Parashar ${ }^{2}$, 3 , Chiman Kumari", Kamla Kant ${ }^{5}$, Ashok Rastogi ${ }^{6}$ and Ashutosh Kumar ${ }^{1, *}$
}

1Department of Anatomy, All India Institute of Medical Sciences (AIIMS), Patna, India; ${ }^{2}$ School of health systems studies, Tata Institute of Social Sciences, Mumbai, India; ${ }^{3}$ Oxford Policy Management, Oxford, UK; ${ }^{4}$ Department of Anatomy, Postgraduate Institute of Medical Education and Research (PGIMER), Chandigarh, India; ${ }^{5}$ Department of Microbiology, All India Institute of Medical Sciences (AIIMS), Bathinda, India; ${ }^{6}$ Department of Forensic Medicine and Toxicology, All India Institute of Medical Sciences (AIIMS), Patna, India

*For correspondence: drashutoshkumar@aiimspatna.org

[Abstract] The ongoing coronavirus disease-2019 (COVID-19) pandemic has raised significant public health issues which need to be attended. To enable efficient handling of the situation and prevent the spread of the epidemic, healthcare professionals require various standard operating procedures (SOPs). Emerging evidence suggests high infectivity of the novel coronavirus strain-severe acute respiratory syndrome virus-2 (SARS-CoV-2)-causing COVID-19. The remains and wastes of COVID-19 patients can be a potential source of the virus exposure to the healthcare professionals if not handled with adequate precaution. Various institutions have issued SOPs in this regard, but a comprehensive approach is missing, which creates difficulty in interpretation and application of these SOPs. We have developed a comprehensive protocol for disposal of remains and wastes of the COVID-19 patients. We are following this protocol at our institution without any untoward event until date.

Keywords: COVID-19, SARS-CoV-2, Dead body, Waste management, Guidelines, Safe-disposal

[Background] Handling and disposal of the remains of the dead during the ongoing pandemic of coronavirus disease-2019 (COVID-19) are one of the most important and demanding aspects for the health care systems globally. COVID-19 is caused by a novel coronavirus strain (a positive sense single stranded RNA virus)-severe acute respiratory syndrome virus-2 (SARS-CoV-2). Emerging evidence suggests that SARS-CoV-2 has high infectivity (Atkinson and Petersen, 2020). The remains and wastes of COVID-19 patients can be a potential source of the virus exposure to the healthcare professionals, hence should be handled with adequate precaution. It is important as the health care system has to ensure that the dead body of a COVID-19 patient should not become a source of the infection, and demanding because of the varied religious beliefs and cultural practices that are associated with the way of disposing the dead body around the globe. In order to enable efficient handling of the remains and wastes of COVID-19 patients by the healthcare professionals, a stepwise protocol of standard operative procedures (SOPs) is essential. The emphasis should be on making the SOPs comprehensive enough for easy interpretation and application. 
A recent report (Sriwijitalai and Wiwanitkit, 2020) regarding the death of a forensic practitioner working in Bangkok, Thailand after contracting the virus from dead COVID-19 patient indicated the risk of transmission of the virus via dead bodies. This incidence has called for a protective protocol for handling the remains and wastes of the COVID-19 patients. Institutions like WHO (World Health Organization), CDC (Centers for Disease Control and Prevention, USA), Department of Health of different governments country wise (such as Ministry of Health and Family Welfare, MoHFW, Government of India; Department of Health, Hong Kong), etc. have laid down the protocols regarding the handling and disposal of the dead during COVID-19 (References 3-6). Though these protocols do elaborately explain the procedure for the same but are often difficult to interpret, and hence the application becomes inconvenient.

Here we have provided a set of instructions to be carried out in a sequential manner for the handling of remains and wastes of the COVID-19 patients providing additional details for precautions and safety measures, protecting gears and disinfecting materials. This protocol will help healthcare professionals taking quick on-spot decisions and avoiding exposure risks while handling the remains and wastes of COVID-19 patients.

\section{Materials and Reagents}

1. Liquid Soap

2. Water

3. $70 \%$ ethyl alcohol

4. EPA (the United States Environmental Protection Agency) registered disinfectant (Reference 7) (such as Sodium hypochlorite with a final concentration of $1 \%$ )

\section{Equipment}

1. Personal protective equipment (PPE) which includes
a. Nitrile gloves
b. Water-resistant gown/plastic apron over water repellent gown
c. N95 mask
d. Full-length cover shoes/boots
e. Goggles or face shield to protect eyes from the splashes

2. Measuring container

3. Plastic sheets for wrapping the body of the deceased

4. Zipper closed leak-proof transparent plastic bag ( $150 \mu \mathrm{m}$ thick)

5. Tags

6. Gauge pieces

7. Spray bottle

8. Coloured Bins (Yellow, Red, White, Blue)

9. Non-chlorinated plastic bags with hazard sign (Figure 1) (Yellow, Red) 


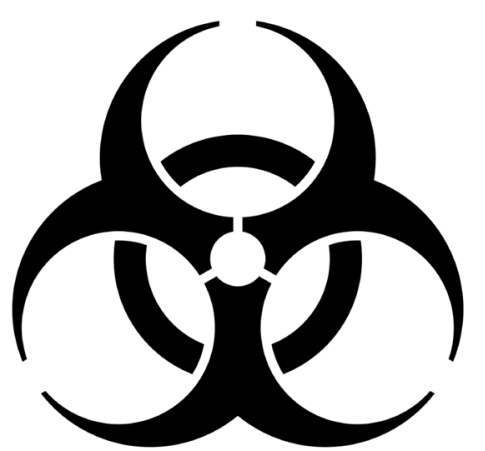

Figure 1. Bio-hazard Symbol (Reference 10)

10. Translucent, puncture, leak and tamper-proof White bags

11. Blue water proof cardboard boxes/containers

12. Incinerator

13. Industrial micro-wave/hydroclave/shredder

\section{Procedure}

A. Handling of the dead body by health care professionals (Tables 1-2) (Figure 2) 
Table 1. The general recommendation for all persons handling the dead body of COVID-19 patients

1. The body should be handled by trained staffs while maintaining a high standard of personal hygiene such as washing hands with liquid soap and water or proper use of alcohol-based hand rub

2. Use of personal protective equipment (PPE) which includes:
a. Nitrile gloves
b. Water-resistant gown/ plastic apron over water repellent gown
c. Surgical mask
d. Full length cover shoes/ boots
e. Use goggles or face shield to protect eyes from splashes

3. Do not smoke, drink or eat. Do not touch the eyes, mouth or nose.

4. Avoid use and injury from needles and/or sharps during the examination of the dead body as well as later when dealing with the waste disposal and decontamination. All needle and sharps disposal should be done in the designated compartments.

5. Remove PPE after handling of the dead body and wash hands with liquid soap and water immediately.

6. In case of percutaneous injury or mucocutaneous exposure to blood or body fluids of the dead body, the injured or exposed areas should be washed with running water and soap for several minutes and inform your supervisor for prophylactic treatment and quarantine.

7. Clinical waste and its management are to be done according to the biomedical waste management criteria.

8. All the surfaces that came in contact with the patient, soiled linen and waste material, along with the reusable equipment should be disinfected using $70 \%$ ethyl alcohol for small areas-reusable dedicated equipment (e.g., thermometers) or Sodium hypochlorite at $1 \%$ for surface disinfection. Bodily fluids and blood stained wastes are to be first disinfected with Sodium hypochlorite at $1 \%$ and then disposed of as per the biomedical waste management rules. 
Table 2. Group specific guidelines for disposal of the dead body of COVID-19 patients

\begin{tabular}{|c|c|c|c|}
\hline & Health Care Professionals (HCP) & Mortuary Staff & Funeral Workers \\
\hline \multirow{5}{*}{$\begin{array}{l}\text { Personnel } \\
\text { protection and } \\
\text { cleaning of the } \\
\text { dead body }\end{array}$} & $\begin{array}{l}\text { PPE should be properly put on by the } \\
\text { staff handling the body }\end{array}$ & \multirow{9}{*}{$\begin{array}{l}\text { Autopsies or embalming of } \\
\text { dead bodies of COVID-19 } \\
\text { patients expose staff to the } \\
\text { unwarranted risk and } \\
\text { should generally be } \\
\text { prohibited. In case autopsy } \\
\text { is essential medico-legally, } \\
\text { it should be done under } \\
\text { strict precautionary } \\
\text { measures as specified by } \\
\text { concerned institutional } \\
\text { guidelines. (Reference 4) }\end{array}$} & $\begin{array}{l}\text { PPE should be properly } \\
\text { put on by the staff } \\
\text { handling the body }\end{array}$ \\
\hline & $\begin{array}{l}\text { Tagging the body for identification as } \\
\text { infectious }\end{array}$ & & $\begin{array}{l}\text { Avoid direct contact with } \\
\text { blood or body fluids from }\end{array}$ \\
\hline & $\begin{array}{l}\text { Removal of tubes, drains and } \\
\text { catheters from the body }\end{array}$ & & the dead body \\
\hline & $\begin{array}{l}\text { Disinfect and dress the wound } \\
\text { drainage and needle puncture holes } \\
\text { with permeable material }\end{array}$ & & \\
\hline & $\begin{array}{l}\text { The body should be cleaned and } \\
\text { dried }\end{array}$ & & \\
\hline \multirow[t]{4}{*}{$\begin{array}{l}\text { Dead body } \\
\text { packaging for } \\
\text { transport }\end{array}$} & $\begin{array}{l}\text { The dead body should be first placed } \\
\text { in a leak-proof transparent plastic } \\
\text { bag ( } 150 \mu \mathrm{m} \text { thick) and zipper closed. } \\
\text { NO pins or stapling should be done. }\end{array}$ & & \multirow[t]{3}{*}{$\begin{array}{l}\text { The body should not be } \\
\text { exposed out of the double } \\
\text { layer covering for viewing }\end{array}$} \\
\hline & $\begin{array}{l}\text { A second layer of the cover is } \\
\text { required, which can be either a } \\
\text { wrapping with a mortuary sheet or } \\
\text { placing the body in an opaque body } \\
\text { bag. }\end{array}$ & & \\
\hline & $\begin{array}{l}\text { The body bag should be cleaned with } \\
1 \% \text { Sodium Hypochlorite solution or } \\
\text { bleach and then should be air dried. }\end{array}$ & & \\
\hline & $\begin{array}{l}\text { Remove and dispose of the PPE in } \\
\text { the container with lids marked for } \\
\text { solid waste as per bio-medical waste } \\
\text { disposal rules, and sanitize hands } \\
\text { with water and soap. }\end{array}$ & & $\begin{array}{l}\text { Remove and dispose of } \\
\text { the PPE in a container } \\
\text { with lids marked for solid } \\
\text { waste as per bio-medical } \\
\text { waste disposal rules, and } \\
\text { sanitize hands with water } \\
\text { and soap. }\end{array}$ \\
\hline
\end{tabular}




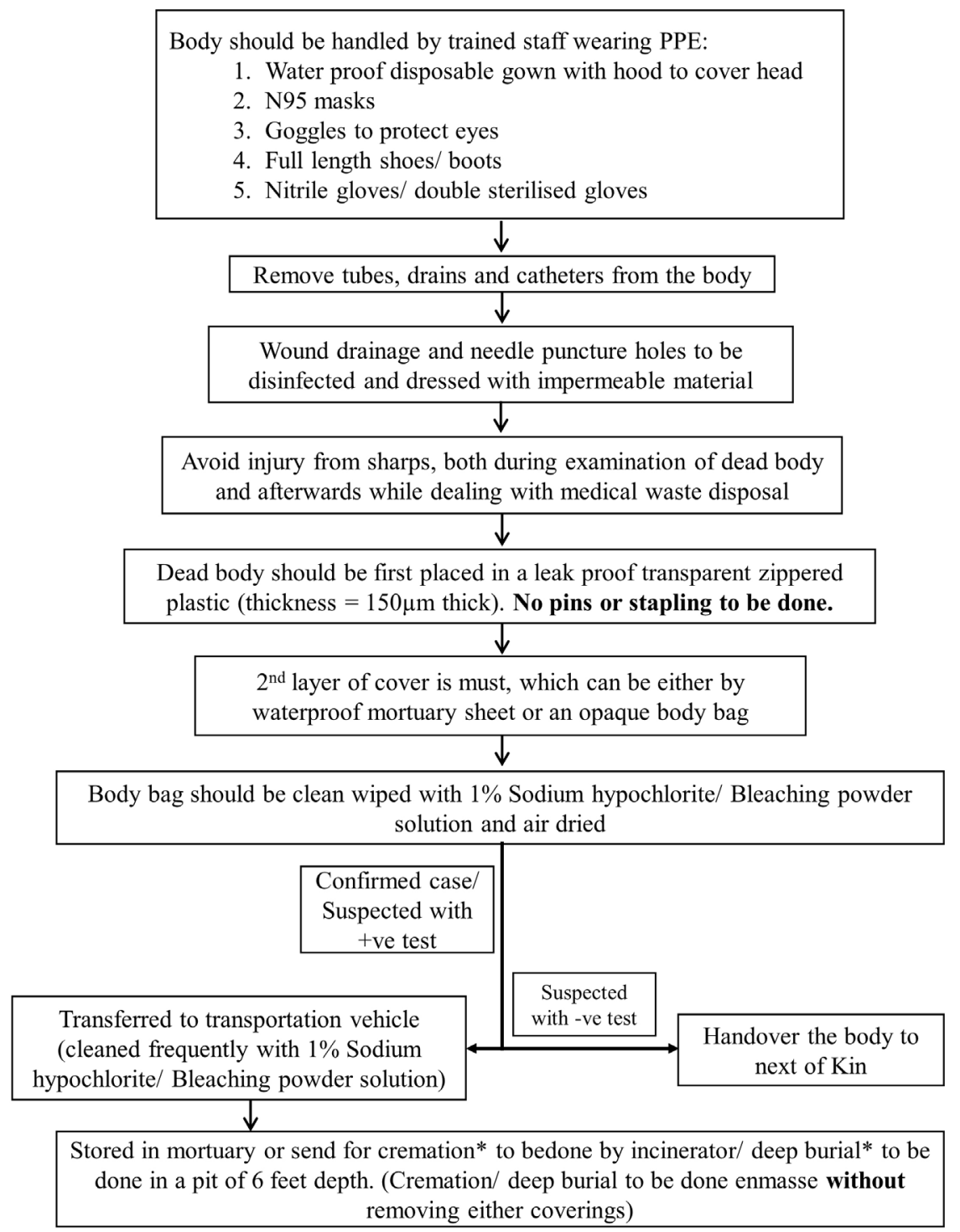

*Cremation / deep burial of Covid 19 patients should be done by authorities in presence of Kin.

\# Clean all the surfaces that came in contact with dead body with $1 \%$ Sodium hypochlorite/ Bleaching powder solution)

Figure 2. Flowchart for steps of handling dead bodies of Confirmed/ Suspected COVID-19 patients

1. The body should be handled by trained and healthy (non-immunocompromised with no active respiratory infections) staffs (who have undergone evaluation of performance before executing the protocol) after maintaining a high standard of personal hygiene by washing hands with liquid soap and water or proper use of alcohol-based hand rub.

2. Donning of the personal protective equipment (PPE) is to be done in the following sequence (Reference 8): 
a. Perform hand hygiene by washing hands with soap and water for $60 \mathrm{~s}$ or rubbing hands with alcohol-based hand rub for $30 \mathrm{~s}$.

b. Put on the gown covering your feet and head.

c. Put on shoe covers.

d. Wash your hand with soap and water for $60 \mathrm{~s}$ or rubbing hands with alcohol-based hand rub for $30 \mathrm{~s}$.

e. Put on the mask.

f. Put on eye protection gears.

g. Put on the gloves.

3. Prepare 3 litre solution of EPA registered disinfectant (Reference 7 ) (such as $1 \%$ Sodium hypochlorite solution is prepared by mixing $2,700 \mathrm{ml}$ of water with $300 \mathrm{ml}$ of stock Sodium hypochlorite) with the help of measuring container and transfer the solution in a spray bottle.

4. Shift the body on a plastic sheet big enough to wrap the body (dimensions $=7 \times 6$ feet).

5. Avoid use and injury from needles and/ or sharps during the examination of the dead body. Remove the tubes, drains and catheters from the body of the deceased and close the puncture sites with the help of rubber or plastic adhesive tape in order to prevent any leakage. All needle and sharps disposal should be done in the designated compartments.

6. Pack the nostrils and oral orifice with gauge piece.

7. Spray the entire body with $1 \%$ Sodium hypochlorite and wait for it to dry.

8. Now, wrap the body in the plastic sheet sealing the same with adhesive plastic tape (remember, no stapling or pinning is to be done to avoid puncturing the sheet leading to leakage).

9. Spray the wrapped sheet with $1 \%$ Sodium hypochlorite and wait for it to dry.

10. Transfer the wrapped body in a zipper closed leak-proof transparent plastic bag ( $150 \mu \mathrm{m}$ thick).

11. Spray the plastic bag with $1 \%$ Sodium hypochlorite and wait for it to dry.

12. Bodybag should be tagged, which should bear the name, age, sex, address and COVID-19 test status of the deceased.

13. Now, transfer the body with the bag on to the transportation vehicle for being shifted to the mortuary.

14. Doffing of the personal protective equipment (PPE) should be done in the following sequence (Reference 8) (Before doffing of the PPE, goggles or face shield, gloves, boots, water-resistant plastic gown must be sprayed with $1 \%$ sodium hypochlorite and allowed to dry):

a. Remove the gloves.

b. Remove the gown.

c. Perform hand hygiene by washing hands with soap and water for $60 \mathrm{~s}$ or rubbing hands with alcohol-based hand rub for $30 \mathrm{~s}$.

d. Remove the eye protective gear.

e. Remove the mask.

f. Perform hand hygiene by washing hands with soap and water for $60 \mathrm{~s}$ or rubbing hands with alcohol-based hand rub for $30 \mathrm{~s}$. 
15. Dispose of the PPE in the container with lids marked for solid waste as per bio-medical waste disposal rules, and sanitize the hands with water and soap.

B. Handling of the body by mortuary staff (Table 2)

1. Staff at the mortuary should wear the disposable surgical cap, mask, gown, gloves and shoe cover while handling the dead body brought in a sterilized body bag.

2. The mortuary cooler cabin (maintained at $4{ }^{\circ} \mathrm{C}$ ), where the body (brought in the body bag) is to be kept, should also be tagged with identifying facts of the deceased to prevent any misadventure.

3. Autopsies or embalming of the dead bodies of COVID-19 patients may expose staff to unwarranted risk hence should be prohibited. In case autopsy is essential medico-legally, it should be done under strict precautionary measures (Reference 4; Hanley et al., 2020).

4. While returning the body to next of the kin after test results (for viral RNA) are reported, one must ensure that the correct body is being handed over and to the authentic kin. Use of mask and gloves by the recipient of the body should be recommended.

5. If the test result is positive for the viral RNA (testing of each case should be done at least twice by the independent centres before declaring the patient positive), then the concerned authorities should be informed for maintaining the data as well as to ensure that the body bag remains unopened until being cremated or buried.

C. Handling of the body at Funeral homes/Cremation/Burial site (Table 2)

1. The transportation to the funeral place in case of the confirmed positive cases should be done under the supervision of government officials, and only trained staff should handle the dead body at the crematorium/or burial ground.

2. If the deceased is COVID-19 positive, then the body should be cremated or buried in the presence of government officials to ensure that the relatives have not opened the bag at any time during the transit or have handled the body without taking precautionary measures.

3. If the deceased is COVID-19 positive, the body bag can be opened just enough as to visualize the face to the relatives watching from at least 2-meter distance, and the staff should be wearing the full personal protective equipment (PPE) as being explained previously.

4. If the deceased is COVID-19 negative, then the body can be handled by the relative and the last rites can be performed as per will or religion of the deceased.

5. Dispose of the PPE in the container with lids marked for solid waste as per bio-medical waste disposal rules (References 10-12), and sanitize hands with water and soap.

D. Handling and disposal of the waste generated while caring a COVID-19 patient (Table 3) (References 10-12) 
Table 3. Biomedical wastes categories with their collection, packaging, treatment, processing and disposal options (References 10-12)

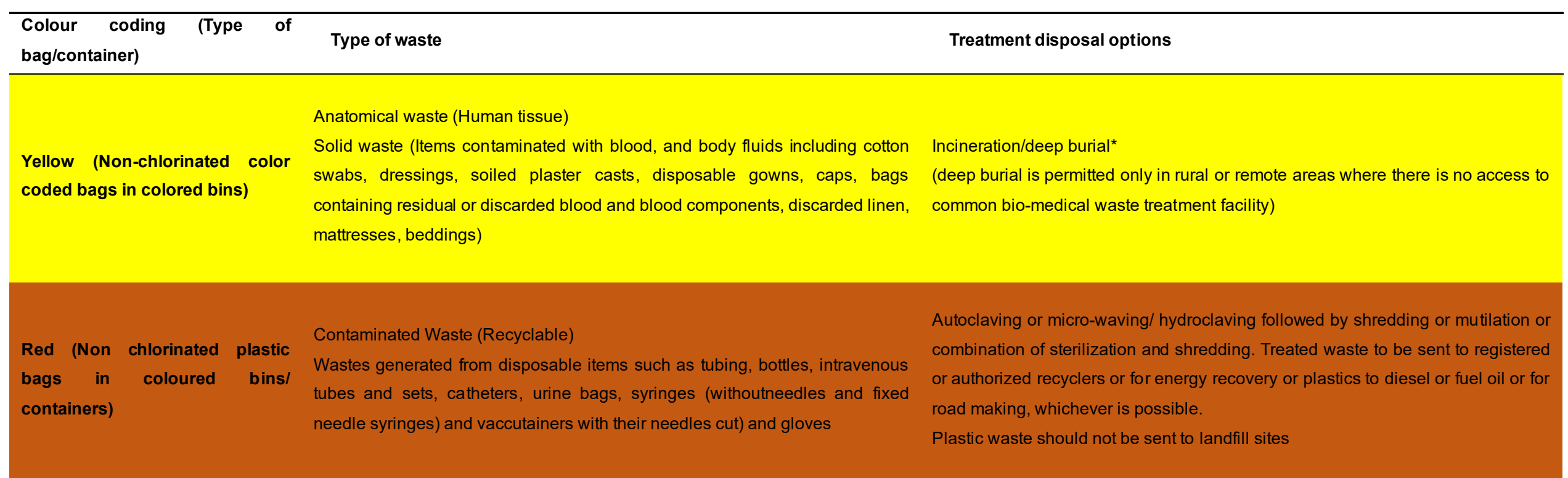

Needles, syringes with fixed needles, needles from needle tip cutter or burner, White (Translucent, puncture, scalpels, blades, or any other contaminated sharp object that may cause leak \& tamper proof) puncture and cuts. This includes both used, discarded and contaminated meta sharps
Autoclaving or Dry Heat Sterilization followed by shredding or mutilation or encapsulation in metal container or cement concrete; combination of shredding cum autoclaving; and sent for final disposal to iron foundries (having consent to operate from the State Pollution Control Boards or Pollution Control Committees) or sanitary landfill or designated concrete waste sharp pit
Blue (Water proof card board

boxes/ containers)
Glassware waste - Broken or discarded and contaminated glass including medicine vials and ampoules
Disinfection (by soaking the washed glass waste after cleaning with detergent and Sodium Hypochlorite treatment) or through autoclaving or microwaving or hydroclaving and then sent for recycling 
1. The wastes are categorized and colour-coded into solid (yellow); liquid; contaminated waste (recyclable-red and non-recyclable-yellow); waste sharps-white/translucent and glassware wastes - blue.

2. The liquid waste is to be treated with EPA registered hospital disinfectant and discharged into drains.

3. Solid wastes comprising of human tissues, items contaminated with the blood of the patient, and body fluids including cotton swabs, dressings, soiled plaster casts, and disposable caps, masks, gowns, and shoe cover, bags containing residual or discarded blood and blood components, discarded linen, mattresses, beddings are to be kept in non-chlorinated yellow plastic bags inside yellow coloured bins. This categorical waste is to be disposed of by incineration (or deep burial is permitted only in rural or remote areas where there is no access to common bio-medical waste treatment facility).

4. Contaminated waste which is recyclable, i.e., waste generated from disposable items such astubings, bottles, intravenous tubes and sets, catheters, urine bags, syringes (without needles and fixed needle syringes) and vacutainers with their needles cut and gloves should be kept in non-chlorinated red plastic bags inside the red coloured bins. These are disposed of by autoclaving or micro-waving or hydroclaving followed by shredding or mutilation or combination of sterilization and shredding. Treated waste should be sent to registered or authorized recyclers or for energy recovery or plastics to diesel or fuel oil or for road making, whichever is possible.

5. The translucent, puncture, leak \& tamper-proof white coloured bags in white-coloured bins are used for keeping the contaminated sharps such as needles, syringes with fixed needles, needles from needle tip cutter or burner, scalpels, blades, or any other contaminated sharp object that may cause puncture and cuts. This includes used, discarded and contaminated metal sharps. These are disposed of by autoclaving or dry heat sterilization followed by shredding or mutilation or encapsulation in a metal container or cement concrete; a combination of shredding cum autoclaving; and are sent for the final disposal to iron foundries (having consent to operate from the State Pollution Control Boards or Pollution Control Committees) or sanitary landfill or designated concrete waste sharp pit.

6. Glassware waste such as broken or discarded and contaminated glass including medicine vials and ampoules are kept in blue coloured waterproof cardboard boxes/ containers. These are then disposed of by disinfection- either by soaking the washed glass waste after cleaning with EPA registered disinfectants (Reference 7) (such as detergent and 1\% Sodium Hypochlorite treatment) or through autoclaving or microwaving or hydroclaving and then sent for recycling.

7. Plastic waste should not be sent to landfill sites.

8. All the containers and bins are to be marked with the universal biohazard symbol (Figure 1).

\section{Acknowledgments}

We consulted related guidelines issued by World Health Organization (WHO), Centers for Disease 
Control and Prevention, USA, and Ministry of Health and Family Welfare (MoHFW), Government of India, and Government of Hong Kong for the preparation of this protocol. Authors express their sincere gratitude to above mentioned organizations.

\section{Competing interests}

Authors declare there are no competing interests. No funding was received for this work.

\section{Ethics}

Ethical issues related to the disposal of human remains and wastes in a hospital setting were considered during the preparation of this protocol.

\section{References}

1. Atkinson, B. and Petersen, E. (2020). SARS-CoV-2 shedding and infectivity. The Lancet 395(10233): 1339-1340.

2. Sriwijitalai, W. and Wiwanitkit, V. (2020). COVID-19 in forensic medicine unit personnel: Observation from Thailand. J Forensic Leg Med 72: 101964.

$\begin{array}{llllll}\text { 3. Apps.who.int. (2020). } & \text { Retrieved } 6 \text { May 2020, from }\end{array}$ https://apps.who.int/iris/bitstream/handle/10665/331538/WHO-COVID-19-IPC DBMgmt2020.1-eng.pdf? mod=article_inline.

4. Coronavirus Disease 2019 (COVID-19). Centers for Disease Control and Prevention. (2020). Retrieved 6 May 2020, from https://www.cdc.gov/coronavirus/2019-ncov/hcp/guidancepostmortem-specimens.html.

$\begin{array}{lllll}\text { 5. Mohfw.gov.in. (2020). } & \text { Retrieved } 6 \text { May 2020, from }\end{array}$ https://www.mohfw.gov.in/pdf/1584423700568 COVID19GuidelinesonDeadbodymanagement. pdf.

6. Chp.gov.hk. (2020). Retrieved 6 May 2020, from https://www.chp.gov.hk/files/pdf/grp-guidelinehp-ic\%20precautions_for_handling_and_disposal_of_dead_bodies_en.pdf.

7. List N: Disinfectants for Use Against SARS-CoV-2 | Pesticide Registration | US EPA https://www.epa.gov/pesticide-registration/list-n-disinfectants-use-against-sars-cov-2 Accessed: 2020-05-06

$\begin{array}{llllll}\text { 8. Apps.who.int. (2020). } & \text { Retrieved } 6 & \text { May } & \text { 2020, from }\end{array}$ https://www.who.int/csr/resources/publications/putontakeoffPPE/en/.

9. Hanley, B., Lucas, S. B., Youd, E., Swift, B. and Osborn, M. (2020). Autopsy in suspected COVID-19 cases. J Clin Pathol 73(5): 239-242.
10. Apps.who.int.
(2020).
Retrieved
6
May 2020,
from https://www.who.int/water sanitation health/medicalwaste/en/guidancemanual1.pdf. 
11. Coronavirus Disease 2019 (COVID-19). Centers for Disease Control and Prevention. (2020). Retrieved 6 May 2020, from https://www.cdc.gov/infectioncontrol/pdf/guidelines/environmentalguidelines-P.pdf.

12. WHO. (2014). Safe management of wastes from healthcare activities. $2^{\text {nd }}$ edition. https://www.who.int/water_sanitation_health/publications/safe-management-of-wastes-fromhealthcare-activities/en/. 